Case Report

\title{
Emotional Freedom Techniques for Stroke Rehabilitation: A Single Case Study
}

Sue Anne Fuller ${ }^{1,+}$, Peta Stapleton ${ }^{2,+, *}$

1. Finding Me with EFT, Labrador, Queensland, Australia; E-Mail: hello@sueannefuller.com

2. School of Psychology, Bond University, Queensland 4229, Australia; E-Mail: pstaplet@bond.edu.au

$\dagger$ These authors contributed equally to this work.

* Correspondence: Peta Stapleton; E-Mail: pstaplet@bond.edu.au

Academic Editor: Gerhard Litscher

Special Issue: Mind-Body Approaches that are Revolutionizing the Health Field

OBM Integrative and Complementary Medicine

2021, volume 6 , issue 4

doi:10.21926/obm.icm.2104038
Received: June 17, 2021

Accepted: October 13, 2021

Published: October 26, 2021

\begin{abstract}
A 37-year-old female with a history of complex trauma, anxiety and depression was treated with Emotional Freedom Techniques (EFT) supplemented with guided imagery within the first 24 hours of having a stroke that affected the right side. CT scans indicated a haemorrhage and brain clot. Surgery was delayed as another seizure was expected. Interventions occurred during COVID-19 restrictions. The patient then engaged in 90 minutes of EFT every day over the course of a week while in hospital. After seven days she was discharged, and there were significant reductions in depression, anxiety and pain, and mobility returned. Upon discharge the patient had evident improvement in balance and coordination and successfully completed a driving test within the weeks that followed. Subsequent CT scans reveal very little scaring or evidence of the stroke, blood pressure remained stable, and no medication was warranted. This case study presents the practitioner's perspective of the sessions provided.
\end{abstract}

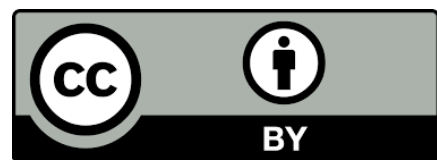

(C) 2021 by the author. This is an open access article distributed under the conditions of the Creative Commons by Attribution License, which permits unrestricted use, distribution, and reproduction in any medium or format, provided the original work is correctly cited. 


\section{Keywords}

Stroke; emotional freedom techniques; tapping; guided imagery; visualization; cerebral; single case; depression; anxiety; trauma

\section{Introduction}

Stroke is the leading cause of long-term disability causing significant morbidity and mortality worldwide [1]. The majority of strokes are ischemic (caused by a blockage of an artery) although hemorrhagic strokes (the rupture of a blood vessel) also occur. Both conditions cause local hypoxia that damages brain tissue and results in significant functional and mood issues. While stroke is often more likely to occur with age, it often affects patients under 65 years [2]. Reports suggest $10 \%$ occur in patients younger than 50 years (termed young stroke; [3]) and two million young people each year worldwide are affected by young stroke [3]. Researchers and health professionals typically agree that contributing risk factors range from an unhealthy diet, smoking habits, high blood pressure and diabetes [2], however the casual link between these factors in young stroke is considered weak [4].

Complications from stroke include physical and functional disabilities, emotional complications and cognitive deficits. A Swedish study of stroke survivors indicated assistance with balance and walking difficulties to be a priority in older adults, while young stroke patients ranked post-stroke fatigue the highest need [1]. While stroke has now transitioned from an untreatable, unpreventable disease to a highly treatable and preventable disease, post-young stroke quality of life has been proposed to be affected by level of cognitive dysfunction, depression symptomology and poststroke complications (e.g., epilepsy, [3]). Treatment in this age group is considered paramount. While researchers do agree rehabilitation strategies should be individualized [1], stroke rehabilitation typically focusses on reducing disabilities and handicaps to improve independence [5]. Young stroke patients are expected to have a better functional prognosis compared to older patients [6-8] yet have been found to have a worse prognosis regarding memory, anxiety, and depression $[9,10]$.

\subsection{Post Stroke Mood Issues in Young Stroke Patients}

Post stroke depression has been reported to affect approximately one-third of individuals [11], however there is no consensus for treatment for mood issues post stroke. The most current Evidence-Based Review of Stroke Rehabilitation [11] indicates goal-setting programs or home visits may not be beneficial for improving mood related outcomes [12], and that traditional talk therapies such as Cognitive Behaviour Therapy (CBT) does not improve activities of daily living or quality of life $[13,14]$. The literature is mixed regarding the effectiveness of CBT for improving post-stroke depression [13] and also mixed for music therapy [15], physical activity [16], and speech therapy for mood concerns [17-18]. 


\subsection{Emerging Psychological Interventions}

Given the percentage of patients reporting mood and psychosocial problems post stroke [11], a significant amount of studies has explored possible interventions to prevent and/or treat psychosocial problems [19-22]. While the effects are modest, information, emotional support, practical advice and motivational support are all cited as being vital in the rehabilitation stage [23]. Psychological intervention for this group is as essential as physical rehabilitation, and as nurse Lanza (2006) shared post her own stroke "If stroke only caused paralysis and a danger of death, it would be a terrible affliction, yet the biggest tragedy of stroke lies in its mental effects" [24].

One emerging psychological intervention centred around reducing stress is Emotional Freedom Techniques (EFT). While EFT has not yet been subjected to clinical trials for stroke patients, case studies indicate promising outcomes. EFT is a manualised evidence-based stress reduction technique that utilises elements of cognitive therapy with physical stimulation of acupressure points [25]. Efficacy has been established for depression, anxiety, phobias, and posttraumatic stress disorder (PTSD, [26]) and changes in biochemistry such as cortisol, blood pressure, immunity and an epigenetic potential to affect gene expression associated with PTSD symptomology has been established [27-30]. Systematic reviews and meta-analyses have indicated large effects for anxiety, depression and PTSD [31-34]. EFT is suggested to affect amygdala activity, and the hippocampus (memory), both of which play a role in the decision process when one decides whether something is a threat. EFT has also been shown to lower cortisol levels $[27,28]$ and deactivate neural mechanisms that trigger undesirable emotions or behaviours. It is therefore logical that reducing this limbic system hyperarousal will allow for greater prefrontal cortex activity.

The EFT process involves patients rating a concern (e.g., distressed feeling or discomfort) on a Subjective Unit of Distress scale (SUDS [35]) zero to 10. A subjective measure of zero would represent an absence of distress and 10 would be the highest rating. Patients then vocalise their distress in a setup statement accompanied by an acceptance statement while physically tapping with two fingers on the side of the hand point (see Figure 1). For example, "Even though I have this worry about xxxx, I accept I feel this way". The patient then manually stimulates (taps) the acupressure points in Figure 2, while stating a reminder phrase from the setup statement (usually the main concern e.g., "this worry"). The process is typically repeated until the patient's SUDS rating is low. 


\section{Tapping Points}

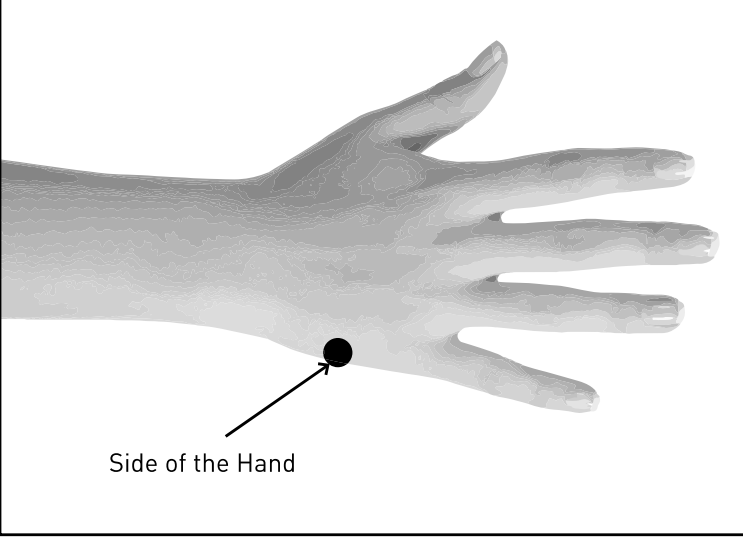

Figure 1 Side of the hand EFT Acupoint. Copyright granted Peta Stapleton, 2019.

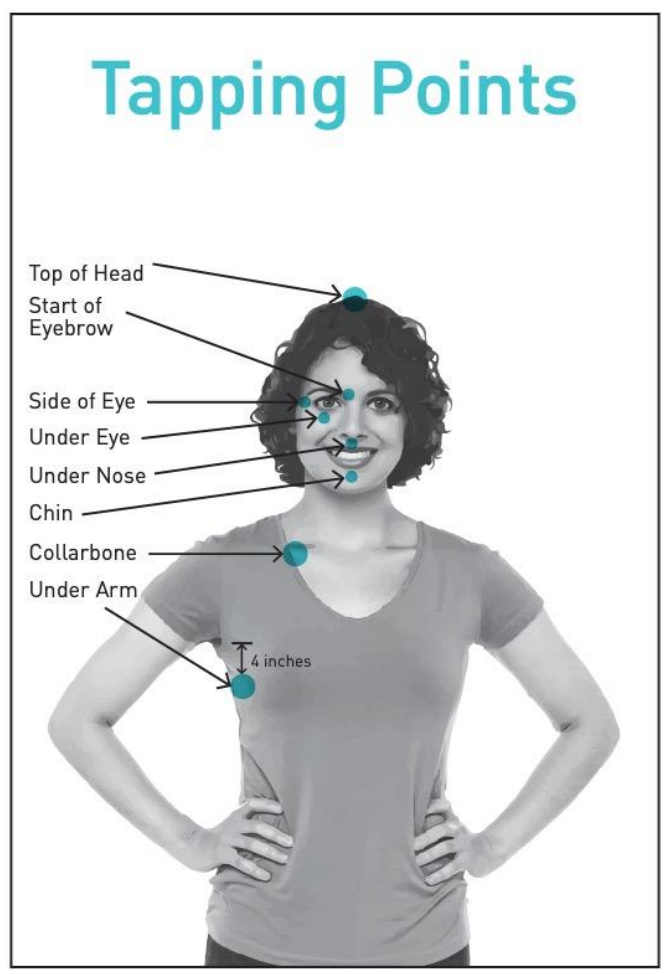

Figure 2 EFT Acupoints. Copyright granted Peta Stapleton, 2019.

\subsection{The Present Study}

This paper focuses on the application of EFT for a young stroke patient during the first week postincident. Because single case study designs provide rich qualitative information about relevant phenomenological processes [36], this is an appropriate way to explore the patient's experience and outcomes. This case study is not a report of quantitative outcomes, but a single narrative as a 
way of learning through story. The narrative also presents the practitioner's perspective of the sessions, and examines the patient's journey through the practitioner's eyes. It is not designed as a teaching tool of how to apply EFT for post stroke for readers.

\subsection{Approach}

While research through narrative may typically focus on communication styles between patient and practitioner, or personal illness experiences, this case study was not pre-designed. The nature of young stroke occurs without warning, and it was only in the months following the incident did the EFT practitioner shape and process her therapy notes to share the story. Thus, a strict interpretive and phenomenological tradition has not been utilised here, although the practitioner's commentary is presented.

\section{Method}

\subsection{Participant Information}

The patient was a 37-year-old female with a history of complex trauma, anxiety and depression. She had been receiving a disability pension due to her high anxiety, complex PTSD and severe depression. Her typical tolerance to stressful situations was extremely low. She had previously had two near-fatal car accidents and other life-threatening experiences resulting in a phobia related to hospitals and confinement.

The patient suffered a haemorrhagic stroke that affected the right side. Surgery addressed the bleed and a brain clot. Because no cause could be medically identified, the patient was not prescribed any medication during her eight-day admission other than paracetemol.

\subsection{Practitioner Information}

The first author was next of kin (her mother) and also a certified EFT practitioner and because of this was able to have daily contact through the hospital. The interventions were delivered via telephone due to her daughter being in isolation.

\subsection{Overview of the Sessions}

Sue-Anne outlines the nature of the neurological event (for the purpose of this narrative):

"My daughter was behind the wheel of the car when she had a stroke at the property gate of her home. It left her paralysed down her right side and understandably, terrified. She was unsure how long she lay on the road beside her car until someone found her. She was unable to move".

Scans at the local country hospital revealed a brain bleed (haemorrhage) and blood clot. She was immediately flown to another State for emergency neurological assessment. Quarantine restrictions due to COVID-19 resulted in her being in isolation. The patient was prepared for surgery to stem the bleed, although the timing was uncertain due to the external lockdown.

Because of her daughter's traumatic history and low tolerance of medical services Sue-Anne shares her concerns as a mother:

"I feared she might not have the will to live. I was feeling trapped, as I couldn't be at her bedside and overwhelmed by the thought of her being alone. I made the decision to be emotionally present 
and support her with my somatic training approaches. I consciously began to 'hold space' for her healing and highest good. In the past I have felt overwhelmed by my children's challenges. This time was different; I had a sense of certainty as I had committed to my own personal peace procedure years prior (a process in EFT) and had a strong sense of inner peace."

Sue-Anne is a trained Neuro Linguistic Programming and EFT practitioner and began to use these approaches for her own personal overwhelm and worry. She shares the next step once her daughter had surgery:

"Thankfully, once she (her daughter) was assigned a bed, she agreed to work with me as she did not know what else to do. Her mind was already spinning with anxiety, she was rehearsing how much worse her life was going to be if she was confined to a wheelchair. Some years prior she was given a dose of the incorrect medication while hospitalised and suffered a negative reaction to the point of becoming paralysed by fear. She remembered the relief from our tapping experience then and agreed to work with me daily, via FaceTime, to ease her emotional distress."

At this point the hospital staff assisted her daughter with accessing Facetime on her cell phone, with Sue-Anne, she began tapping on presenting issues. The frequency was daily, often twice a day for 90 minutes at a time.

While her daughter did not have pain, her body felt numb and heavy. The lifeless weight of her right side, from head to toe terrified her and this was potentially her future reality. Tapping sessions focussed on these aspects and presenting issues.

Sue-Anne describes the general pattern of their sessions on Facetime:

"Our sessions usually began with tapping and breathing to bring my daughter to a felt-sense of body state regulation. Some days we tapped on a story title, this helped to keep her safe (e.g., "My life keeps getting worse"). I simply worked with whatever was the most urgent matter at the time. Sometimes I guided her mindfully to focus on interesting aspects of her room or the sound of my voice to help with grounding, as she had a habit of spacing out.

Each session focussed on calming her nervous system by focusing on her breath and tapping on the specific presenting issue that session. I didn't include body sensations or emotions until the SUDS level dropped. An example was "Even though I can't believe it, I'm here now doing the best I can. Reminder phrase, I can't believe it".

Other reminder phrases that were used included:

"I can't find the words", and "This is too much for me".

Once the SUDS dropped below 5 out of 10 we tapped on felt body sensations and emotions. For example, "Pounding heart, all this worry, tight jaw, thumping headache, all this numbness, tired and exhausted".

Thankfully her speech was only mildly impacted, and we were able to notice marked improvements in her articulation fairly quickly.

It was important she was able to soothe herself with the EFT technique. She found it helpful to use it on herself in my absence, particularly to ease minor frustrations such as feeding herself with her less dominant hand and also craving a cigarette (which she could not have inside)."

Sue Anne highlights that because of her daughter's previous negative experiences in the hospital setting, most interactions with medical staff were very triggering for her. Because of COVID-19 they were wearing protective clothing and their faces were covered (masks) and the lack of facial contact resulted in her feeling hypervigilant, nauseated and she could not sleep. Sue-Anne shares: 
"She (daughter) began suffering flashbacks of traumatic unresolved memories in her sleep and during the day. Her brain was hyper alert as she scanned all the possible horrific, imagined, future events that may occur (including a potential seizure). However, if she felt, saw, heard or imagined anything distressing we tapped on it. On average we tapped for 90 minutes every day. She also applied the stress management technique to her negative thoughts in between our sessions. The idea of being aware of her thoughts was quite confronting at first, as she usually had a few strategies to avoid or suppress her feelings (e.g., cigarette smoking \& alcohol consumption). A typical example setup statement was "Even though I have resistance to being aware of my thoughts, I have too many uncontrollable thoughts, I accept myself anyway."

\subsubsection{A Set Back}

On the third day her daughter received the prognosis that she may never walk again from one specialist. Another gave some hope saying she had some chance of regaining a little mobility, however it would take at least six months of 'hard work' in the hospital Rehabilitation Unit.

Sue-Anne shares:

"The doctor's report and prognosis were highly distressing and threatened to counteract my daughter's progress. The words kept looping in her head. This news had struck a core wound of feeling 'helpless' and it derailed her. She was again contracted by fear. It reminded her of her old story, 'Nobody helps me, I can't be helped'".

These reactions were targeted with EFT in the daily sessions and her daughter became more relaxed and coherent. She began questioning the possibility of a different outcome. This provided a profound pivotal moment and her daughter stated: "No -body knows what my body, mind and spirit are capable of, not even me. I'm going to believe I will walk again, and it won't take six months."

Because her daughter had a clear intention and a goal, Sue-Anne reported her confidence increased by the hour. Sue-Anne shares:

"It was delightful to witness the shift in her thinking. She began to express all the things in her life she had previously taken for granted. Her persona changed and she started to feel movement in her fingers and toes."

\subsubsection{Supplementary Interventions}

It was at this time Sue-Anne introduced her daughter to active visualisation techniques which she reframed as a way to 'play' with her daughter's over-active mind. After a session using EFT, her daughter was able to visualise her limbs moving. She imagined each movement, the thought of taking a step, the message being sent from her brain to her nervous system, bones and muscles.

Sue-Anne shares the process:

"The exercise of visualising green healing energy flooding her injured brain gave her a sense of excitement. Guided meditation allowed her shrink to the size of a particle and enter into her skull to locate the sites of her brain trauma. She imagined herself cleaning the injured tissue. She had seen the scans and $x$-rays, and these provided her with a clear picture of the affected sites. Using her imagination, she was able to lovingly perform imaginary surgery and remove the damaged tissue."

This exercise also became the content for EFT set up statements. For example, they said "Even though my brain is inflamed and bruised, I accept how I feel about myself and my body". 
Can you imagine Sue-Anne's surprise less than a week after hospitalisation when her daughter announced she had, 'stood up,' by herself! Her daughter had woken that day with a clear picture of herself standing unassisted and the words 'I can do this!' in her mind. She used the left side of her body to manoeuvre herself off the bed. The nurse came in to see her standing there. While she was not able to move from that position and initially felt completely off balance, she was beside herself with excitement.

From this point her daughter began shuffling slowly, and while she reported it was exhausting, she kept focusing on the image in her mind - of walking and driving again. She had one picture in her mind: that she was going to walk and drive again.

Sue-Anne's daughter was flown back to the Rehabilitation Unit in her home State eight days after the stroke. The doctors confirmed she was making an outstanding recovery and they had no doubt she would walk again. Sue-Anne continued to work via Facetime addressing her daughter's fears as they arose, particularly her flashbacks about driving.

Sue-Anne's daughter was released from Rehabilitation after two weeks. Several weeks later she passed a test to be able to drive again. The following neural scans reveal very little scaring or evidence of the stroke. She has not been prescribed any medication. And her blood pressure remained stable. She was quick to reach out if she felt overly stressed or anxious however, these incidences became less and less frequent. Sue-Anne's daughter was surprised when she noticed she was driving on the freeways without any anxiety, and instead felt calm and at ease.

At the time of this article (some three months post-stroke) Sue-Anne's daughter's right arm sometimes shakes if she becomes overly tired or physically pushes herself too far. However, the traumatic memory of the stroke appears to have been transformed. It is now simply a story about something that happened to her, and she has no compulsion to keep reliving it. In fact, there are aspects of the experience she cannot remember, as the memory appears to have been changed. Her daughter commented "I sometimes seems as if the whole stroke thing was a dream".

Sue-Anne comments on the conclusion of this journey with her daughter: "I am forever grateful for the powerful tool of tapping. I was confident in meeting my child at the place of her pain, confusion and overwhelm. I am not so sure we would have achieved this degree of positive intervention and fast outcome if we had not had this life-changing, evidence-based tool at our fingertips. It certainly delivered hope and results in an extraordinary situation. In my heart, I believe we were instrumental in a miracle. Words cannot express my utter faith in these techniques to align the mind and body to the realm of the profound and the body's innate wisdom to heal".

\subsubsection{Final Reflection}

Sue-Anne reflected in the 12-months after the incident:

"I'm still mind boggled how she [daughter] managed to cut through all those distractions and addictions to create such outstanding Tapping results in what she would perceive as an alienating and hopeless situation. Plus, she had very little faith in the process as she was convinced, she was beyond help. The process created deep inner miracles. Her personality has had a makeover, she's far more grounded in herself."

Sue-Anne contemplated that while her daughter's event was unexpected and difficult, she was in wonder of how impactful and life-changing EFT was for her, perhaps because it was delivered in 
the 10-day window. She expressed hope that describing the narrative would help to raise awareness in the traditional fields of how techniques such as EFT may support the healing process.

\section{Discussion}

Medical literature commonly refers to a critical period for patients where the maximum outcome will be achieved. Termed a 'window of opportunity' [37] this period is significant for many medical conditions and can range from hours to months. For trauma patients, it has been suggested there is a golden hour or silver day after injury, and that it is paramount for recovery that treatment be swift [38].

Animal research too has since identified a 10-day window of time that exists immediately after a traumatic event before significant neuron and synaptic changes happen [39]. A single stressful event appears to increase amygdala activity, not immediately, but after a 10-day period. Dependent on the molecule N-Methyl-D-Aspartate Receptor (NMDA-R), an ion channel protein on nerve cells known to be crucial for memory functions, the brain's architecture appears to be malleable to change after this period. The increase in glutamate levels with stress in the amygdala appears to be long lasting and the authors propose this increase could act on NMDA receptors to create an ideal situation that eventually leads to a delayed formation of new dendritic spines and delayed strengthening of the structural basis of synaptic connectivity [39]. The delayed effects proposed may therefore have implications for interventions post event, and ideally within the first 10-days. The suggestion is that interventions that target inactivation of NMDARs in the amygdala may block the delayed effects on synaptic connectivity, and therefore future chronic stress conditions.

The presented case study and the timing of the EFT treatment may have impacted this receptor and intervened with glutamate levels, amygdala activity and formation of new dendrite spines that would assist with memory formation. Research suggests the nervous system is capable of plasticity and the dendritic spine is suggested to be the major site of this activity [40]. Dendritic spine development is known to be affected by brain trauma [40] and is also implicated in psychiatric symptomology such as addiction [40], Autism [41], Alzheimer's disease [42], and memory and learning [40]. Dendritic spine alterations can occur in minutes (often linked to initial memory formation) and increased alterations over time affecting storage of long-term memories. When brain injury (e.g., stroke) interferes with this process, neural cell death and dendritic spine degeneration occurs. This degeneration and synapse loss may significantly contribute to functional impairments post traumatic brain injury.

\subsection{Limitations and Further Opportunities}

It is acknowledged that the intervention in this case was delivered by the client's mother. Although she was a certified EFT practitioner, it does raise ethical questions of bias and potential transference. Furthermore, the intervention was delivered via Facetime and the client did have a brain injury, possibly affecting the validity of the sessions. However, given the nature of the pandemic at the time, and the inability of another trained practitioner to visit in person, her mother as next of kin was the only approved person for contact. In this case it was possibly the most appropriate way to support the client. Finally, often narratives and personal experiences as a research strategy are focused on the participants' stories, but in this case the lived experience and context was provided by the practitioner. Future research in this area would benefit from the 
patient's narrative, as well as a structured EFT intervention program for stroke patients, quantitative data examining the patient's psychological symptomatology and biomarker outcomes.

\subsection{Conclusions}

The ability of interventions to impact dendritic degeneration and instead allow for regeneration post traumatic injury seems paramount. While this is an individual investigation of a stress reduction technique, the patient's outcomes and subsequent gains appear to flag that her stroke has not had the typical long-lasting effect one would expect. Reduction in cortisol levels [27, 28], inflammation and other biomarkers [29] have been previously noted in EFT research, and given the relationship of glutamate levels with stress in the amygdala within the window of opportunity, it is proposed interventions such as EFT may be highly effective to prevent long-term negative outcomes. While further research in humans on the 10-day window are naturally recommended, the ability to impact long-term changes through stress-reducing psychological interventions is promising.

\section{Acknowledgments}

The authors acknowledge the patient for sharing her story and outcomes in this case study.

\section{Author Contributions}

S.F. delivered the intervention and documented the qualitative notes. P.S. wrote the main paper.

\section{Competing Interests}

Both authors may derive remuneration for presenting on the topic of EFT because of their level of expertise.

\section{References}

1. Rudberg AS, Berge E, Laska AC, Jutterström S, Näsman P, Sunnerhagen KS, et al. Stroke survivors' priorities for research related to life after stroke. Top Stroke Rehabil. 2021; 28: 153158.

2. Barthels D, Das H. Current advances in ischemic stroke research and therapies. Biochim Biophys Acta Mol Basis Dis. 2020; 1866: 165260.

3. Rutten-Jacobs LC, Maaijwee NA, Arntz RM, Van Alebeek ME, Schaapsmeerders P, Schoonderwaldt $\mathrm{HC}$, et al. Risk factors and prognosis of young stroke. The future study: A prospective cohort study. Study rationale and protocol. BMC Neurol. 2011; 11: 109.

4. Rutten-Jacobs LCA. Long-term prognosis after stroke in young adults. Nijmegen: Radboud University; 2014.

5. Cotoi A, Teasell R. Evidence-based review of stroke rehabilitation. London: EBRSR Research Group; 2018.

6. Nedeltchev K, der Maur TA, Georgiadis D, Arnold M, Caso V, Mattle HP, et al. Ischaemic stroke in young adults: Predictors of outcome and recurrence. J Neurol Neurosurg Psychiatry. 2005; 76: 191-195. 
7. Marini C, Russo T, Felzani G. Incidence of stroke in young adults: A review. Stroke Res Treat. 2010; 2011: 535672.

8. Marini C, Totaro R, De Santis F, Ciancarelli I, Baldassarre M, Carolei A. Stroke in young adults in the community-based L'Aquila registry: Incidence and prognosis. Stroke. 2001; 32: 52-56.

9. Waje-Andreassen $U$, Naess $H$, Thomassen L, Eide GE, Vedeler CA. Arterial events after ischemic stroke at a young age: A cross-sectional long-term follow-up of patients and controls in western Norway. Cerebrovasc Dis. 2007; 24: 277-282.

10. Waje-Andreassen U, Thomassen L, Jusufovic M, Power KN, Eide GE, Vedeler CA, et al. Ischaemic stroke at a young age is a serious event-final results of a population-based long-term follow-up in Western Norway. Eur J Neurol. 2013; 20: 818-823.

11. Saikaley M, Iruthayarajah J, Harnett A, Salter K, Foley N, Mehta S, et al. Post stroke depression (Chapter 18). In: Evidence-based review of stroke rehabilitation. London: EBRSR Research Group; 2018.

12. Jones F, Gage H, Drummond A, Bhalla A, Grant R, Lennon S, et al. Feasibility study of an integrated stroke self-management programme: A cluster-randomised controlled trial. BMJ Open. 2016; 6: e008900.

13. Kootker JA, Rasquin SM, Lem FC, van Heugten CM, Fasotti L, Geurts AC. Augmented cognitive behavioral therapy for poststroke depressive symptoms: A randomized controlled trial. Arch Phys Med Rehabil. 2017; 98: 687-694.

14. Visser MM, Heijenbrok-Kal MH, van 't Spijker A, Lannoo E, Busschbach JJ, Ribbers GM. Problemsolving therapy during outpatient stroke rehabilitation improves coping and health-related quality of life: Randomized controlled trial. Stroke. 2016; 47: 135-142.

15. Raglio A, Zaliani A, Baiardi P, Bossi D, Sguazzin C, Capodaglio E, et al. Active music therapy approach for stroke patients in the post-acute rehabilitation. Neurol Sci. 2017; 38: 893-897.

16. Gezer H, Karaahmet OZ, Gurcay E, Dulgeroglu D, Cakci A. The effect of aerobic exercise on stroke rehabilitation. Ir J Med Sci. 2019; 188: 469-473.

17. Topcuoglu A, Gokkaya NK, Ucan H, Karakuş D. The effect of upper-extremity aerobic exercise on complex regional pain syndrome type I: A randomized controlled study on subacute stroke. Top Stroke Rehabil. 2015; 22: 253-261.

18. Konecny P, Elfmark M, Horak S, Pastucha D, Krobot A, Urbanek K, et al. Central facial paresis and its impact on mimicry, psyche and quality of life in patients after stroke. Biomed Pap. 2014; 158: 133-137.

19. Hackett ML, Anderson CS, House A, Halteh C. Interventions for preventing depression after stroke. Cochrane Database Syst Rev. 2008; 3: CD003689.

20. Forster A, Brown L, Smith J, House A, Knapp P, Wright JJ, et al. Information provision for stroke patients and their caregivers. Cochrane Database Syst Rev. 2012. Doi: 10.1002/14651858.CD001919.pub3.

21. Knapp P, Young JO, House AL, Forster AN. Non-drug strategies to resolve psycho-social difficulties after stroke. Age Ageing. 2000; 29: 23-30.

22. Redfern J, McKevitt C, Wolfe CD. Development of complex interventions in stroke care: A systematic review. Stroke. 2006; 37: 2410-2419.

23. Kirkevold M, Bragstad LK, Bronken BA, Kvigne K, Martinsen R, Hjelle EG, et al. Promoting psychosocial well-being following stroke: Study protocol for a randomized, controlled trial. BMC Psychol. 2018; 6: 12. 
24. Lanza M. Psychological impact of stroke: A recovering nurse's story. Issues Ment Health Nurs. 2006; 27: 765-774.

25. Church D. The EFT manual. Fulton: Energy Psychology Press; 2013.

26. Church D. Clinical EFT as an evidence-based practice for the treatment of psychological and physiological conditions. Psychology. 2013; 4: 645-654.

27. Church D, Yount G, Brooks AJ. The effect of emotional freedom techniques on stress biochemistry: A randomized controlled trial. J Nerv Ment Dis. 2012; 200: 891-896.

28. Stapleton P, Crighton G, Sabot D, O'Neill HM. Reexamining the effect of emotional freedom techniques on stress biochemistry: A randomized controlled trial. Psychol Trauma. 2020; 12: 869-877.

29. Bach D, Groesbeck G, Stapleton P, Sims R, Blickheuser K, Church D. Clinical EFT (Emotional Freedom Techniques) improves multiple physiological markers of health. J Evid Based Integr Med. 2019; 24: 2515690X18823691.

30. Church D, Yount G, Rachlin K, Fox L, Nelms J. Epigenetic effects of PTSD remediation in veterans using clinical emotional freedom techniques: A randomized controlled pilot study. Am J Health Promot. 2018; 32: 112-122.

31. Clond M. Emotional freedom techniques for anxiety: A systematic review with meta-analysis. J Nerv Ment Dis. 2016; 204: 388-395.

32. Church D, Stapleton $P$, Yang A, Gallo F. Is tapping on acupuncture points an active ingredient in Emotional Freedom Techniques? A systematic review and meta-analysis of comparative studies. J Nerv Ment Dis. 2018; 206: 783-793.

33. Nelms JA, Castel L. A systematic review and meta-analysis of randomized and nonrandomized trials of clinical emotional freedom techniques (EFT) for the treatment of depression. Explore. 2016; 12: 416-426.

34. Sebastian B, Nelms J. The effectiveness of emotional freedom techniques in the treatment of posttraumatic stress disorder: A meta-analysis. Explore. 2017; 13: 16-25.

35. Wolpe J. The practice of behavior therapy. 2nd ed. New York: Pergamon Press; 1973.

36. McLeod J. Case study research in counselling and psychotherapy. London: SAGE Publications; 2012.

37. Kitzinger J, Kitzinger $C$. The 'window of opportunity'for death after severe brain injury: Family experiences. Sociol Health IIIn. 2013; 35: 1095-1112.

38. Lerner EB, Moscati RM. The golden hour: Scientific fact or medical "urban legend"? Acad Emerg Med. 2001; 8: 758-760.

39. Yasmin F, Saxena K, McEwen BS, Chattarji S. The delayed strengthening of synaptic connectivity in the amygdala depends on NMDA receptor activation during acute stress. Physiol Rep. 2016; 4: e13002.

40. Frankfurt $M$, Luine $V$. The evolving role of dendritic spines and memory: Interaction(s) with estradiol. Horm Behav. 2015; 74: 28-36.

41. Sudhof TC. Neuroligins and neurexins link synaptic function to cognitive disease. Nature. 2008; 455: 903-911.

42. Dorostkar MM, Zou C, Blazquez-Llorca L, Herms J. Analyzing dendritic spine pathology in Alzheimer's disease: Problems and opportunities. Acta Neuropathol. 2015; 130: 1-19. 


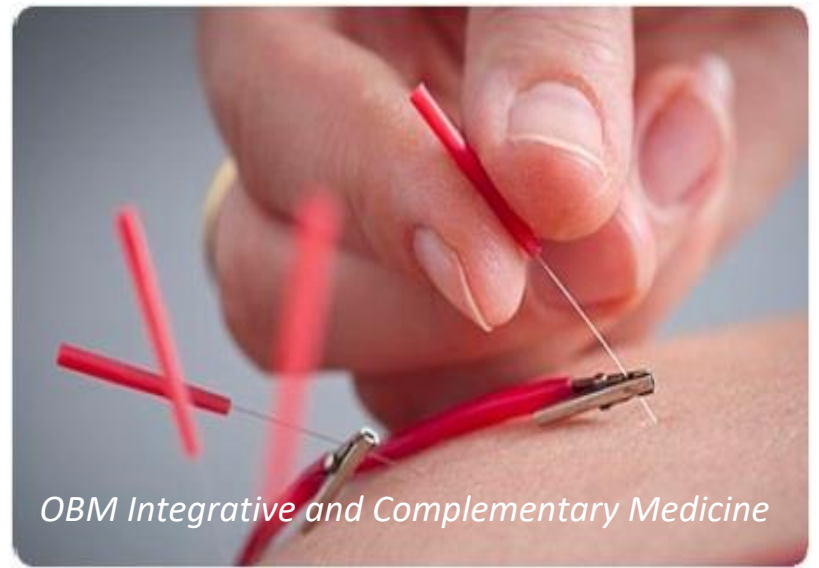

Enjoy OBM Integrative and Complementary Medicine by:

1. Submitting a manuscript

2. Joining in volunteer reviewer bank

3. Joining Editorial Board

4. Guest editing a special issue

For more details, please visit:

http://www.lidsen.com/journals/icm 